\title{
An Investigation of Lexical Cohesion on Indonesian Singer Song
}

\author{
Ahmad Murodi' ${ }^{1}$, Didin Nuruddin Hidayat ${ }^{2}$, Alek Alek ${ }^{3}$ \\ Department of English Education, UIN Syarif Hidayatullah Jakarta \\ ahmadmurodi333@gmail.com,didin.nuruddin@uinjkt.ac.id,alek@uinjkt.ac.id
}

\begin{abstract}
This paper sheds light on investigating the lexical cohesion on an Indonesian singer's song entitled Coke Bottle by Agnez Mo. Lexical cohesion makes up linguistic devices that help to create cohesiveness of the text. Lexical cohesion occurs when two words or more in a text are semantically related somehow-they are related in terms of their meaning. This study's design was a descriptive qualitative that attempted to elaborate the discourse analysis about lexical cohesion in Coke Bottle song by Agnez Mo. Some steps were conducted to collect the data. First, the lyrics that become the documentation were collected by the researcher from lyrics.com, secondly the researcher read the lyrics to understand the text. Third, marking some words included as lexical cohesions in which they will be the real data of this study. The findings revealed that reiteration and collocation are found in the song, but the antonym that is part of reiteration is absent. Above all, repetition is the most commonly used in this song, especially the word I. This seems to show that the songwriter tried to make the song's lyrics match the music's beat, so the song became easy listening, and the listeners can enjoy the music.
\end{abstract}

Keywords: Lexical cohesion, discourse analysis, linguistics

\section{Introduction}

Singing and listening song are the part of Indonesia culture. These cultures which are inherent with Indonesian people that stretches from Sabang to Merauke. Studies about song's lyrics viewed from discourse analysis, especially the lexical cohesion have basically been carried out by many researchers before, both in Indonesian and foreign language. In terms of the aspect of discourse, song lyrics have different patterns and structures from one song to another. Lexical cohesion is a form of interaction of the deep structures of language in building meaningful relationships between the morphological units of language in a text. The morphological units referred to here are, in the form of words, including content words and function words in building meaningfulness of discourse (Paltridge, 2012).

Song lyrics are a combination of words as phrases or simple sentences that prioritize the essence or important words without grammatical perfection. The messages in the song in the texts or sentences contain imperative utterances. This is like the poetry, but the song lyrics are given the tone and accompanied by the music. Song lyrics make up the representations of the language comprising letters that form the words, phrases, and sentences that form linguistic symbols that comprise phonemes, morphemes, structures, and meanings. The words or lyrics in the mixed and combined song should have a relation called cohesion. The words' relationship in the song lyrics will produce grammatical, lexical, denotative, connotative, literal, and figurative meanings. To create a discourse, lexical cohesion comprehension is one aspect that must be considered. Then, the aims and objectives of creating a discourse can be conveyed clearly. The song lyrics' lexical cohesion

Halaman | 15 
can be described semantically and pragmatically in which the lyrics are analyzed in terms of their meaning. Textual analysis is a discourse analysis that relies internally on the text under study. Textual discourse analysis has two scopes of analysis, namely the analysis of grammatical and lexical aspects. Here, lexical cohesion is discussed in the relationship of one lyric to another lyric and how it becomes a unity between lyrics. The discourse's lexical aspect focuses on meaning that relies on semantic relations, namely reiteration and collocation (Hutahaean \& Edward, 2015; Van Dijk, 1999).

The pattern of connection in the outward form of language, especially words, will have its own impact in building harmony and harmony in the meaning of discourse (Halliday \& Hasan, 1976). They further divide lexical cohesion into two aspects: 1) Reiteration, in this form, words or phrases are used equitably in building the harmony and meaning of a sentence so as to build the integrity of the discourse. The pattern of repetition of a word or phrase in a sentence is intended to build the power of meaning or affirmation of a particular purpose in conveying the ideas, thoughts, and feeling of an author; 2) Collocation, this type of lexical cohesion seeks to produce a sentence or expression that simultaneously builds meaning harmony based certain lexical associations on a regular basis. More explicitly, Halliday and Hasan (1976) argued that word pairs can be selected from words that have similar entries, such as numbers, months, weeks, days, colors, and the alike.

Discourse is the highest unit of a language and comprises many words (Fairclough, 2003; Perumal et al., 2015). Because the discourse is the highest unit, it needs to be analyzed deeply to know the content of the lyrics, and discourse analysis to analyze the discourse. Discourse analysis is defined as the study of how speakers combine sentences into broader speech units. Many categories of discourse analysis, one of them is the cohesion. Many scholars proposed cohesion, such as Haliday and Hasan, Tanskanen, and so forth. Cohesion serves to connect elements of sentences to achieve a coherent text, and it is realized using several cohesive devices. The cohesion is divided into two major categories, namely Grammatical Cohesion and Lexical Cohesion (Enyi \& Orji, 2019). Some similarities and differences of the cohesion taxonomy from different scholars, likewise the lexical cohesion. For example, Halliday's and Hasan's lexical cohesion's taxonomy (Halliday \& Hasan, 1976) comprises reiteration and collocation, for the reiteration comprises repetition, synonym, hyponym, meronym, antonym, collocation. Meanwhile, Tanskanen's taxonomy (Tanskanen, 2006) comprises Simple and Complex Repetition, Substitution, Equivalence, Generalization, Specification, Co-specification, Contrast.

Lexical cohesion is one of the cohesion types that ties the text from one word to another. Lexical cohesion occurs when two words or more in a text are semantically related somehow-they are related in terms of their meaning. The lexical cohesion is divided into two major categories: reiteration and collocation (Arifin, 2019). The explanation below describes the definitions of lexical cohesion briefly.

a. Reiteration

Reiteration is a form of lexical cohesion which involves the repetition, synonyms, hyponym, meronym, antonym, and general word.

1) Repetition

Halaman | 16 
Repetition of sounds, words, phrases, sentences, and functions. Repetition commonly occurs in the song lyrics. It seems to show that the songwriter tried to create the rhythm or musical ambiance, stress the particular purpose as the central question for the songwriter, and draw the listeners' attention (Perumal et al., 2015).

2) Synonym

A synonym uses a similar word to refer to another word, and a synonym refers to similarity in meaning but with original words (Luthfiyah. et al., 2015; Silva, 2017). For example, the word 'ascended' is the synonym for the word 'climbed'.

3) Hyponym

Hyponym is the state or phenomenon that shows the relationship between the more general term (lexical representation) and the more specific instances (Jiang \& Hyland, 2017). For example, 'sedan is a kind of car.' In other words, 'car' is the superordinate of 'sedan' ("red is a hyponym of color").

4) Meronym

Meronym is a word that denotes a constituent part or a member of something (Malah et al., 2016). For example, "An apple a day keep doctors away. The fruit is beneficial to health indeed". 'Fruit' in here is superordinate since it includes the word 'apple'.

5) Antonym

An antonym has a meaning opposite to that of another word (Amalia \& Hidayat, 2020), such as hot and cold, short and tall.

6) General word

A general word occurs when a word of general meaning substitutes a more specific one (Olajoke, 2015). For example, "The old bridge can collapse any time. That old thing is not safe at all." The word "thing" is a general word substituting a specific word "bridge."

b. Collocation

Collocation is a combination of two or more words commonly used together (Dewi et al., 2018). These combinations sound 'right' to native English speakers. Other combinations may be unnatural and just sound 'wrong.' (example: fast car, we cannot say rush car, even the word rush has a similar meaning with the word fast).

Some studies have investigated the lexical cohesion in relation to the present study. Pratiwi et al., (2019) researched analysis of lexical cohesion in "Never Say Never" song lyrics; this study employed the taxonomy of Tanskanen's lexical cohesion (Tanskanen, 2006). The study found that the song lyrics contain eleven forms of lexical cohesion, comprising two synonyms, seven repetitions, and two antonyms. Hence, the most frequent occurrence in the data is repetition. Similarly, Enyi and Orji (2019) investigated Lexical Cohesion in Nonfictional Narrative, and the study revealed that Ngugi's narrative was lexically cohesive. The 
cohesive devices found comprise reiteration (near-synonym) - 13 times and repetition 8 times. Other lexical devices deployed by the writer to achieve various textual and communicative functions include: antonyms 4 times; superordinate/hyponym, 2 times; and one complimentary and one cohyponym. Compared to this study, the current study used Hassan and Halliday's lexical cohesion taxonomy in the song. Besides, Wang and Zhang (2019) examined the Lexical Cohesion in Research Articles. This study revealed that the adoption of repetition, synonymy, and meronym significantly related to Introduction, method, Results, and Discussion (IMRD) structure. Furthermore, it is assumed that synonymy is prone to be context-dependent. Meanwhile, hyponymy and antonymy are content-oriented. Compared with what Wang and Zang did in their paper, this study tried to elaborate the lexical cohesion in the international song of Indonesian musicians featuring two American international musicians (Timbaland and T.I), and the title of the song is Coke Bottle.

Referring to the elaboration elucidated above, this research intended to answer the two main questions related to the lexical cohesion of the Coke Bottle song by Agnez Mo with the following questions: (1) what are the cohesive lexical features used in the Coke Bottle song? (2) to what extent is the cohesion level achieved in the Coke Bottle song?

\section{Method}

In this investigation used a qualitative method to reach and answer the main questions posed in study. The reason of using qualitative method of this investigation was that it went beyond identifying frequency and it helped to classify text or song's lyric into categories representing similar meanings (Sögüt, 2018). This study intended to analyze the song's lyric through discourse analysis adopted Hasan and Halliday's taxonomy's lexical cohesion towards the Coke Bottle song by Agnez Mo. The data of this study were written data about the lexical cohesion. Furthermore, the main instrument in collecting data of this research were the researchers and used protocols as additional instrument in order to cover information needed in this study (Creswell, 2012).

A research Instrument is a tool used to collect, measure, and analyze data related to your research interests (Zohrabi, 2013). According to Creswell (2012), an instrument is a tool for measuring, observing, or documenting in one research whether in quantitative or qualitative research. These tools are most commonly used in health sciences, social sciences, and education to assess patients, clients, students, teachers, staff, etc. A research instrument can include interviews, tests, surveys, checklists, and even researchers. Research instrument depends on the model and research method.

The procedures of data collection in this investigation, followed some steps which cover: First, the lyrics that became the documentation were collected by the researchers from lyrics.com. Second, the researchers read the lyrics to understand the text. Third, the researchers marked some words included as lexical cohesions in which they will be the real data of this study. In order to analyze the data, some steps were conducted, such data reduction (because some words are not marked), data display (the data gathered were tabulated to display), and conclusion (the data were then concluded).

The following is the formula to measure the percentage: 
Jurnal Onoma: Pendidikan, Bahasa dan Sastra

\section{$\frac{\text { the number of cohesion device }}{\text { the number of topic units }} \times 100 \%$}

In order to decide the level of cohesiveness, the discourse should be analyzed and have a percentage result, and the following is a level of cohesiveness categorization:

\begin{tabular}{|c|c|}
\hline Categories & Percentage \\
\hline Very high & $>85 \%$ \\
\hline High & $70-85 \%$ \\
\hline Medium & $55-69 \%$ \\
\hline Low & $35-54 \%$ \\
\hline Very low & $<35 \%$ \\
\hline
\end{tabular}

This research limits the lexical cohesion of the discourse found in the lyrics produced by Agnez Mo because, in this song, she collaborated with two International American musicians Timbaland and T.I. This limitation should focus on the lyrics of Agnez Mo because it tried to avoid the ambiguity of the meaning of the lyrics, especially when it turns to words of reference such I, You, and so forth. After all, the word I produced by Agnez differs from the word $I$ produced by Timbaland and T.I.

\section{Results}

In order to display the findings of this research, the researchers tabulated the words into their categorization below:

\begin{tabular}{|c|c|c|c|c|c|}
\hline No & $\begin{array}{l}\text { Types of } \\
\text { Lexical } \\
\text { Cohesion }\end{array}$ & Data & $\begin{array}{c}\text { Number of } \\
\text { cohesive } \\
\text { devices }\end{array}$ & $\begin{array}{c}\text { Percentage } \\
\text { per } \\
\text { cohesive } \\
\text { devices }\end{array}$ & $\begin{array}{c}\text { Whole } \\
\text { song } \\
\text { Percentage }\end{array}$ \\
\hline 1 & Repetition & $\begin{array}{l}32 x \text { (I) } \\
\text { 20x (me, that), } \\
19 x \text { (it, lookin') } \\
17 x \text { (get), } \\
16 x \text { (got) } \\
14 x \text { (I'm, like) } \\
13 x \text { (see, my) } \\
12 x \text { (Coke Bottle, you're, } \\
\text { rubberband, bouncing, at, } \\
\text { curves, bounce, pluck) } \\
\text { 10x (he) } \\
\text { 8x (Imma, real, good, make, } \\
\text { go, side) } \\
7 x \text { (a) }\end{array}$ & 53 & $85.5 \%$ & $52 \%$ \\
\hline
\end{tabular}

Halaman | 19 


\begin{tabular}{|c|c|c|c|c|c|}
\hline & & $\begin{array}{l}5 x \text { (to) } \\
4 x \text { (day, on, little, try, know, } \\
\text { back, and, forth) } \\
3 x \text { (you, but, don't, keep) } \\
2 x \text { (they, care, about, every, } \\
\text { 'em, man, probably, has, no, } \\
\text { chance, can, for, is) }\end{array}$ & & & \\
\hline 2 & Synonyms & $\begin{array}{l}\text { 1. See: lookin', keep their } \\
\text { eyes on, } \\
\text { 2. get: catch, } \\
\text { 3. back and forth: side to } \\
\text { side, }\end{array}$ & 3 & $4.85 \%$ & $3 \%$ \\
\hline 3 & Hyponym & Mama > Woman, & 1 & $1.6 \%$ & $1 \%$ \\
\hline 4 & Meronym & Woman > Mama, & 1 & $1.6 \%$ & $1 \%$ \\
\hline 5 & Antonym & - & 0 & $0 \%$ & $0 \%$ \\
\hline 6 & $\begin{array}{l}\text { General } \\
\text { word }\end{array}$ & day & 1 & $1.6 \%$ & $1 \%$ \\
\hline 7 & Collocation & $\begin{array}{l}\text { Fast car, care about, got } \\
\text { from, }\end{array}$ & 3 & $4.85 \%$ & $3 \%$ \\
\hline \multicolumn{3}{|r|}{ Total } & 62 & $100 \%$ & $61 \%$ \\
\hline
\end{tabular}

\section{Discussion}

The results above are organized based on the lexical cohesion types classification. The words are arranged from the greatest number of words. For an example, the results showed that the word $I$ is repeated 32 times in which it became the highest number of repetition. These words need one syllable to say that is why it is very flexible to put wherever that the songwriter wants. It proved that the word $I$ in one part or sentence is repeated many times, it might seem that the songwriter wants to emphasize the main character which is the singer to be the focus. The repetition in the song is very common occurred in the song lyrics, it is proven by Pratiwi et al. (2019) in their research that repetition is the highest number from all lexical cohesion devices, and they stated that the many repetitions occurred in the song because the songwriter wants to create a good rhythm.

Beside the word $I$ in that becomes the highest number of repetitions, other words also appeared that included as the repetition, the data showed that twenty times repetition emerged for the word me and that, nineteen times repetition of the word it and lookin', seventeen times repetition of the word get, sixteen times repetition of the word got, fourteen times of the word I'm and like, thirteen times repetition of the word see and my, twelve times repetition of the word Coke Bottle, you're, rubberband, bouncing, at, curves, bounce, and pluck, ten times occurrence of the word he, eight times repetition of the word Imma, real, good, make, go, and side. Seven times repetition of the word $a$, five timesjorepetition of the word to, four times repetition of the word day, on, little, try, know, back, and, and forth. Three times Halaman | 20 
repetition of the word you, but, don't, and keep. Twice for the word they, care, about, every, 'em, man, probably, has, no, chance, can, for, and is.

Besides the repetition that commonly occurred in this song lyrics, synonyms, which is the second part of reiteration that means that the word has the same meaning but in a different form are also appeared three devices in the lyrics such the word see in line 3 fits the phrase of keeping their eyeson in line 11 and also the word looking in line 17. The second device is the word get in line 16 matches the word catch in line 25 . The phrase back and forth in line 49 is similar to the phrase side to side in line 50.

The third lxical cohesion device to be analyzed is hyponym, and the word mama is indicated as the hyponym of the word woman. Conversely, the word woman became the meronym of the word mama. The fourth cohesive device is antonym that literally can be interpreted as the word or name of things that have the opposite meaning (Pratiwi et al., 2019). The song lyrics of Coke Bottle did not show the word that is included as the antonym. Then the antonym was absent in this song.

The last category of reiteration is a general word. A general word is used to represent or change specific things (Enyi \& Orji, 2019). The lyrics showed that the word day used in line 10 shown this song is categorized as a general word because day has many specifications, Sunday, Monday, etc. The last type of lexical cohesion is collocation. Collocation occurred when two words or more are combined and have their meaning but cannot be separated or combined with other words. If that happens, it will change the meaning or have no meaning (Hutahaean \& Edward, 2015). The phrase Fast cike categorized as collocation because the word fast is a suitable word that accompanies the word fast and can be changed with theshowush or others. The second phrase is care about that if we change the preposition will have different meaning, and also the third is the phrase got from became the collocation in this song.

Also, the cohesiveness level in the Coke Bottle song is 61\%, which means that this song achieved a medium level of cohesiveness. The score is got from the lyrics that has 102 sentences, then the number of cohesive devices that resulted in 62 devices is divided by 102 . It times a hundred from every part of cohesive devices, then the percentage of cohesive devices are calculated. 
Jurnal Onoma: Pendidikan, Bahasa dan Sastra PBSI FKIP Universitas Cokroaminoto Palopo Volume 7 Nomor 1 Tahun 2021
ISSN 2443-3667 (Print)

ISSN 2715-4564 (Online)

\section{Conclusions}

Based on the results above, it can be concluded that repetition is the most common used in Coke Bottle songs. However, other lexical cohesion devices also appeared to make the lyrics cohesive lexically. Above all, because the whole song's percentage is $61 \%$, it means that the level of cohesiveness in the Coke Bottle song is medium. The researchers realized that this research is not perfect. Many shortcomings are found in this research. The present study suggests that other researchers who want to research lexical cohesion, especially in the song, need to be more concerned about the lyrics or the words analyzed. The study also suggests investigating the grammatical cohesion in the song to make research more valuable.

\section{References}

Amalia, D., \& Hidayat, D. N. (2020). Lexical Cohesion in kid talks: The instagram videos of Mila Stauffer. Insaniyat Journal, 5(1), 36-48.

Arifin, W. L. (2019). A Discourse Analysis on "Under the Same Sun" from Scorpions. Journal of Pragmatic Research, 1(1), 78-88.

Creswell, J. W. (2012). Educational Research (P. A. Smith (ed.); FOURTH EDI). Pearson Education, Inc.

Dewi, A. P., Suastra, I. M., \& Udayana, I. N. (2018). The analysis of American Slang in movie script "The Wolf of Wall Street." Humanis, 22, 1. https://doi.org/10.24843/jh.2018.v22.i01.p01

Enyi, A. U., \& Orji, E. C. (2019). Lexical Cohesion in non-fictional narrative as discourse: A study of Ngugi Wa Thiong'O's Decolonizing the Mind. International Journal of Education and Literacy Studies, 7(3), 83-90.

Fairclough, N. (2003). Analysing discourse: Textual analysis for social research. Psychology Press.

Halliday, M. A. K., \& Hasan, R. (1976). Cohesion in English. Sheck Wah Tong Printing Press.

Hutahaean, S., \& Edward, E. (2015). Kohesi leksikal dalam lirik lagu Craig David. Journal Ilmu Budaya, 11(2), 80-100.

Jiang, F., \& Hyland, K. (2017). Metadiscursive nouns: Interaction and cohesion in abstract moves. English for Specific Purposes Journal, 46(1), 1-14.

Luthfiyah., Alek., \& Fahriany. (2015). An investigation of Cohesion and Rhetorical Moves in thesis abstracts. Indonesian Journal of English Education, 2(2), 145-149.

Malah, Z., Tan, H., \& Rashid, S. M. (2016). Evaluating lexical cohesion in Nigerian newspaper genres: Focus on the editorials. International Journal of Applied Linguistics and English Literature, 6(1), 240-256.

Halaman $\mid 22$ 
Jurnal Onoma: Pendidikan, Bahasa dan Sastra

ISSN 2443-3667 (Print)

PBSI FKIP Universitas Cokroaminoto Palopo

Volume 7 Nomor 1 Tahun 2021

ISSN 2715-4564 (Online)

Olajoke, A. S. (2015). A lexical analysis of an inaugural speech of the speaker of Benue State House of Assembly in Nigeria. Journal of Language Teaching and Research, 6(2), 258264.

Paltridge, B. (2012). Discourse analysis: An introduction (2nd Editio). Bloomsbury Publishing.

Perumal, T., Muthusamy, P., Salleh, C. I., \& Krishnamoorthy, K. (2015). Discourse features in the lyrics of the Tamil Song "Annaiyin Karuvil." Social Sciences and Humanities Journal, 23(4), 1083-1098.

Pratiwi, V. Y., Jayanti, Y. D., \& Syathroh, I. L. (2019). An analysis of lexical cohesion found in "Never Say Never" song lyrics. PROJECT (Professional Journal of English Education), 2(3), 377-384.

Silva, M. (2017). The use of questions to scaffold narrative coherence and cohesion. Journal of Research in Reading, 42(1), 1-17.

Söğüt, S. (2018). Gender representations in high school EFL coursebooks: An investigation of job and adjective attributions. Abant İzzet Baysal Üniversitesi Eğitim Fakültesi Dergisi, 18(3), 1722-1737.

Tanskanen, S.-K. . (2006). Collaborating towards Coherence: Lexical Cohesion in English Discourse. John Benjamins Publishing Company.

Van Dijk, T. A. (1999). Context models in discourse processing. The Construction of Mental Representations During Reading, 123-148.

Wang, J., \& Zhang, Y. (2019). Lexical Cohesion in research articles. Linguistics and Literature Studies, 7(1), 1-12.

Zohrabi, M. (2013). Mixed method research: Instruments, validity, reliability and reporting findings. Theory \& Practice in Language Studies, 3(2). 